\title{
Vehicle Loading Conditions' Influence Over Front Lighting Requirements and Dipped Beam Vertical Leveling Control Method
}

\author{
Ahmet Rodoplu, Hatice Özbek*, Caner Çil \\ TOFAŞ Türkiye Otomobil Fabrikası A.Ş. Bursa, Turkey \\ A. Rodoplu (0000-0002-2764-0978), H. Özbek (0000-0002-8271-284X), C. Cil (0000-0003-0164-4636)
}

\begin{abstract}
This study evaluates the effects of the vehicle body inclination changes on the cut-off (the transition between the lighter and darker portions of the beam) vertical position of dipped beam which is one of the main functions of the headlamp. The functionality of headlamp vertical aiming system and its importance for the driving safety are examined. In case of any change on the vehicle, which effects to the vehicle inclination values, a control method is defined in order to check suitability of cut-off vertical position for every loading conditions defined by regulations. In addition, the calculations are formulated to find required vertical aiming values in order to keep the cut-off position in the range of minimum to maximum values defined by the regulations are formulated. It is concluded that after heavy accessory/configuration changes, major modifications, or new version of model applications on the vehicle make necessary to be checked availability of actual cut-off vertical positions and output values of the headlamp aiming software. In case of aiming software update necessities, new values based on regulated loading conditions can be defined by following formulations.
\end{abstract}

Key words: Automotive, Loading Conditions, Vehicle Inclination, Headlamp, Leveling

\section{INTRODUCTION}

Automobile is a kind of a sum total of the systems which are composed of more than 30.000 pieces and work together in a perfect harmony. Automobiles play a part in human life more than 100 years and they are indispensable transportation devices of today. While they bring easiness and comfort into our life, they also bring some kind of issues such as environmental pollution, noise, accidents etc. In order to keep all of these negative effects under control, governments define some kind of technical and taxational restrictions for car manufacturers or customers. Technical restrictions are followed and controlled by official and technical communities (e.g. ECE, SAE) and certified homologation agencies.

Headlamps illuminate the road space in front of the car and must meet the requirements of all users of the road. In particular, dipped beam functions are subject to legal regulations designed to protect oncoming traffic from being dazzled. (1) Glare is a major consideration in the design of automotive headlamps. Most attention has been given to the problems glare creates when vehicles are meeting. (2)
Any improper position of the cut-off line means a significant risk for the safety and it increases accident risks accordingly. Cut-off line in passing beam has very important function because serve for headlamp aiming. Present system of requirements concerning headlamps is far from perfect. It was historically defined in subjective and descriptive way. Even though changes done in definitions last years the precision of real cut-off line is still insufficient. (3) Therefore, the position of the cut-off line and its tolerances have been defined by official regulations for every particular loading conditions of the vehicle. Out of tolerance positions are exactly forbidden.

The goal of present study was to investigate the influences of loading conditions over the position of cut-off line, to define checking method of current cut-off position availability in case of major modifications or new version studies and to formulate a method to calculate the tension values of the leveling motor in order to fix the cut-off displacement issues.

\subsection{Loading Conditions}

Loading condition means a vehicle loaded to its technically
${ }^{*}$ Corresponding authour

Email: haticeozbek1688@gmail.com
European Mechanical Science, June 2019; 3(2): 75-82

doi: https://doi.org/10.26701/ems.464441

Received: September 27, 2018

Accepted: May 14, 2019 


\begin{tabular}{|l|l|l|}
\multicolumn{2}{|c|}{ Table 1 - Motor vehicles which defined in regulations (1) } \\
\hline & Category & \multicolumn{1}{|c|}{ Vehicle type } \\
\hline
\end{tabular}

permissible mass, as stated by the manufacturer, who shall also fix the distribution of this mass between the axles in accordance with the method described in regulations. (4)

Loading conditions are specified by regulations with regard to vehicle types as shown in Table 1 . These loading conditions cause to displace the cut-off position of dipped beam. Following displacement values must be in tolerances which are defined by regulations belongs to categories referred in Table 1.

\subsection{Cut-Off Line}

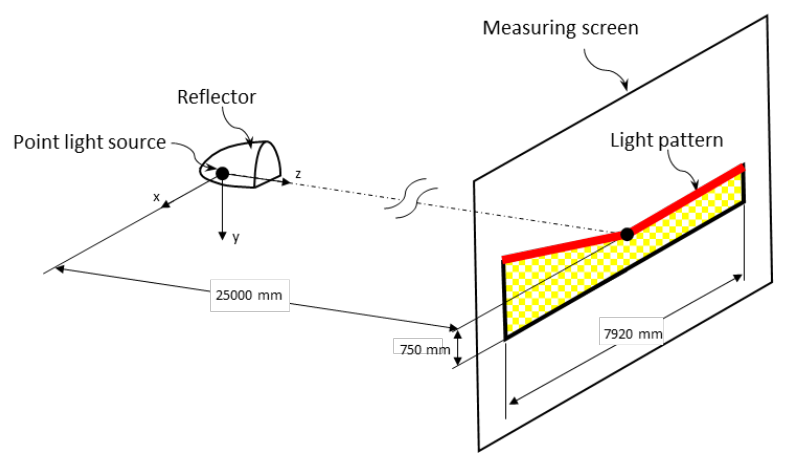

Figure 1 - Measuring conditions set up (5)

The basic element of dipped beam headlights is the "cut-off line". It was intended in European beam pattern as the shape of dipped beam according far road illumination and protection oncoming drive eyes from excessive glare. (3)

Many years, cut-off line is being checked by setting conditions up as described in Figure 1 and judged by comparing the image appeared on the real screen with the descriptive cut-off shape shown in Figure 2.

Red colored line in Figure 2 below describes the cut-off shape as horizontal on the left side and slant line $15^{\circ}$ to the right.

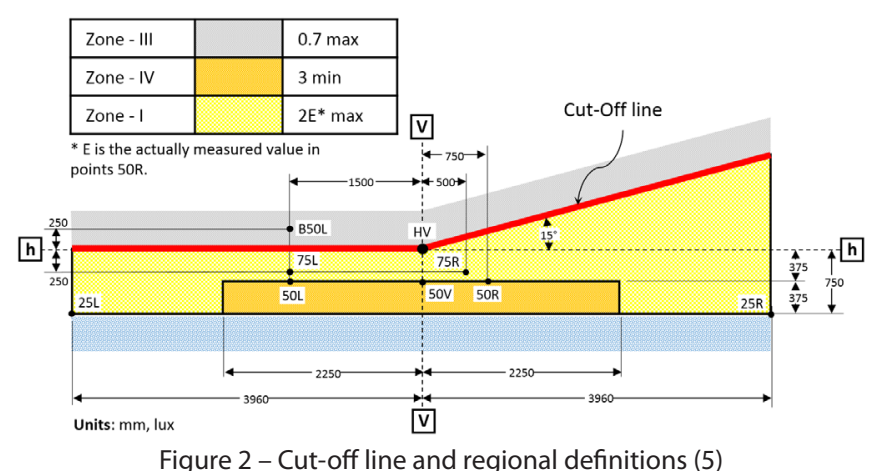

Above described cut-off shape on the screen ensures following road illumination as shown in Figure 3.

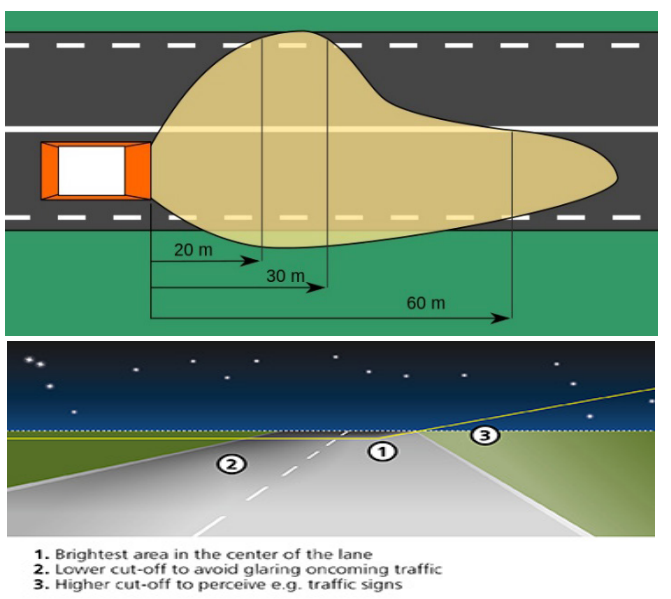

Fig. 3 Influences of the cut-off line over road illumination and driving safety (6)

\subsection{Relation Between Loading Conditions and Cut-Off Vertical Position}

Loaded mass values on axles effect directly to the vehicle body inclinations. For example, if rear luggage boot of the vehicle is loaded with an evenly distributed load to obtain the permissible load on the rear axle, rear side of the vehicle comes closer to the ground and vertical position of the cutoff line is shifted slightly upward. If this vertical displacement of the cut-off goes out of the permissible tolerance range, dipped beam lights dazzle oncoming driver as shown in Figure 5.

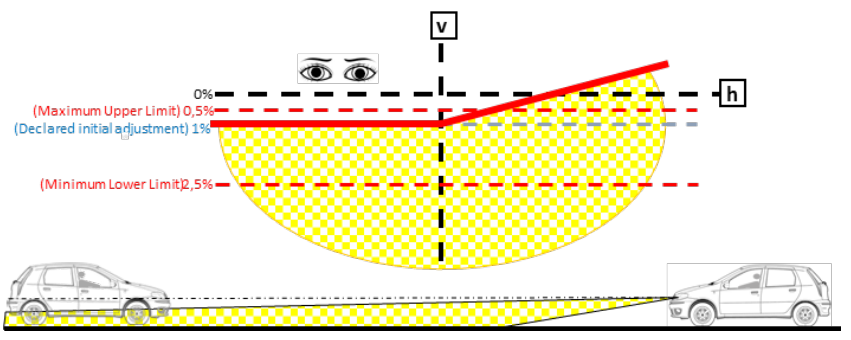

Figure 4 - Influences of the loading conditions over cut-off line position (Driver only, no load)

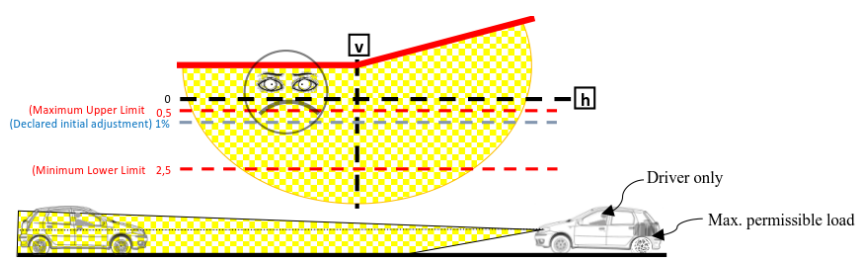

Figure 5 - Influences of the loading conditions over cut-off line position 
(Driver only, maximum permissible load)

In order to measure vertical displacement value of the cutoff line, following conditions in Figure 6 are defined by regulations. (4)

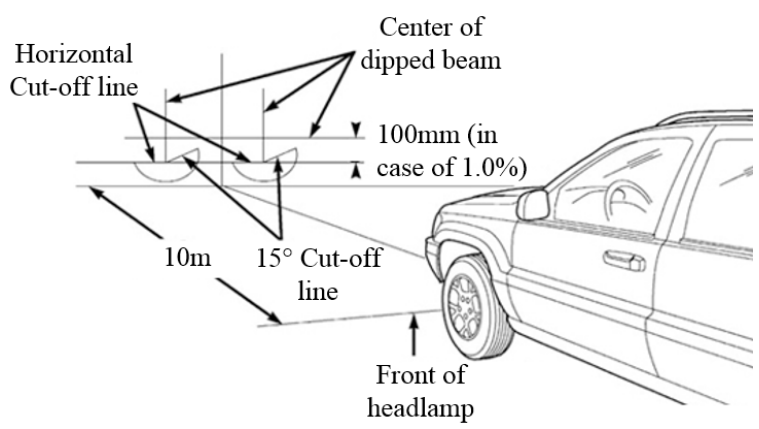

Fig. 6 Cut-off line position measurement conditions under effect of loading conditions

Vertical displacement of the cut-off line is corrected by integrated leveling system of the headlamp and kept inside of permissible tolerance range.

The initial downward inclination of the cut-off of the dippedbeam to be set in the unladen vehicle state with one person in the driver's seat shall be specified within an accuracy of 0.1 per cent by the manufacturer and indicated in a clearly legible and indelible manner on each vehicle close to either headlamp or the manufacturer's plate by the symbol defined in ECE Reg 48. (4)

The value of this indicated downward inclination shall be defined in accordance with paragraph 6.2.6.1.2. of ECE Reg 48. (4)

\subsection{Headlamp Leveling System}

Regulation ECE R48 requires the compensation of vehicle inclination caused by different load conditions since 1998. The compensation of vehicle inclination is realized by driving manual leveling screws in order to compensate manufacturing tolerances and/or driving leveling motor in order to compensate inclinations come from different loading conditions defined in regulations. (4)

\subsubsection{Manual Leveling Mechanism}

At the end of the vehicle production line, cut-off position needs to be adjusted in order to compensate vehicle inclination deviations come from manufacturing operations.

Manual leveling mechanism allows operators or specialists to play with position of the cut-off line following the vehicle inclination.

In Figure 7 red colored movements show vertical adjustment process. Basically, manual vertical adjustment screw is driven by operator, motor group is moved through $\mathrm{X}$ and reflector is slightly rotated accordingly. Therefore, the cutoff line is moved vertically and repositioned to the correct position.

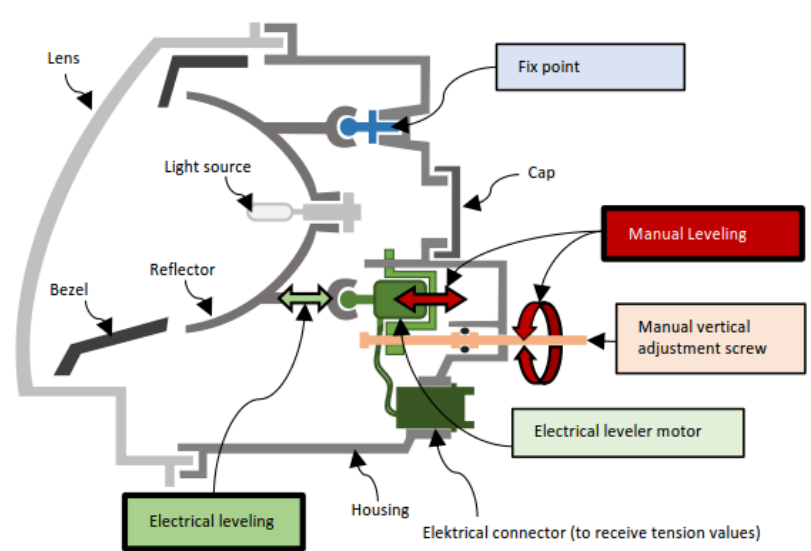

Figure 7 - Headlamp leveling system

\subsubsection{Electrical Leveling System}

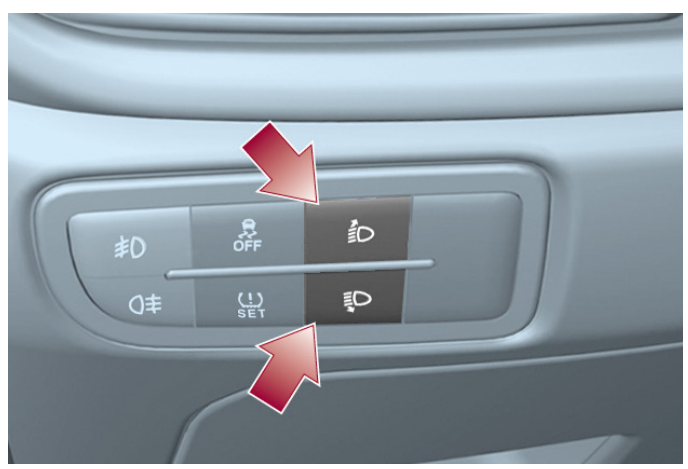

Figure 8 - Driver controlled cut-off leveling buttons (7)

Electrical leveling system allows driver or main control unit of the vehicle to reposition the cut-off line depends on different loading conditions which are defined by regulations. (4)

Table 2 - Cut-off position controller levels (7)

\begin{tabular}{|l|l|}
\hline Level 0 (L0) & The driver + one passenger in the front seat \\
\hline Level 1 (L1) & 4 or 5 person. \\
\hline Level 2 (L2) & 4 or 5 person + permissible maximum load. \\
\hline Level 3 (L3) & The driver + permissible maximum load \\
\hline
\end{tabular}

Driver controllable systems have a controller interface which is composed of moving, rotating or pressing button (see Figure 8). These interfaces commonly have multiple levels which means different cut-off line positions to fulfill regulative requirements for each defined loading conditions. Cutoff line positions for each level are defined by manufacturer according to inclination values of the vehicle body for each loading conditions (See Table 2). Defined cut-off line positions are managed by main control unit which preferred as common for all version of the model. Main control unit sends specific tension values to the vertical adjustment motor of the headlamp for each specified controller level. Motor pivot is repositioned according to received tension value and cut-off line is moved to required position. All of these levels and assigned tension values should be common for each version of the model in order to simplify production and to ensure competitive industrialization. Communization of tension values and main control software accordingly needs to be considered in early development phase of a new model studies.

In this present study, driver controlled leveling system which 
has four levels was examined. Definition of common cut-off line positions and required tension values for each loading conditions was evaluated, control method for availability of actual cut-off line positions for new version applications of current model or major modifications which are able to effect vehicle body inclination values was defined.

\section{METHOD}

\subsection{Simulation of Loading Conditions and Analysis Report Output}

Inclination values of the vehicle body needs to be analyzed during the development of a new model or significant body modifications, heavy accessory/configuration changes of the actual model.

\begin{tabular}{|c|c|c|c|c|c|c|c|c|c|c|}
\hline \multirow{2}{*}{$\begin{array}{l}\text { condizione } \\
\text { standard o }\end{array}$} & \multicolumn{3}{|c|}{ 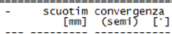 } & 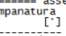 & \multicolumn{2}{|c|}{ 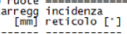 } & \multicolumn{2}{|c|}{ 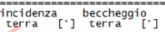 } & \multicolumn{2}{|c|}{$\begin{array}{l}\text { posizizbaricentro } \\
x \\
x\end{array}$} \\
\hline & $\begin{array}{c}\text { ant } \\
\text { pos } \\
.\end{array}$ & $\begin{array}{l}30.4 \\
-39.6\end{array}$ & 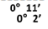 & $\begin{array}{ll}0^{0^{\circ}}-10^{\prime} \\
0^{\circ}-28^{\prime}\end{array}$ & $\begin{array}{l}1144.5 \\
1450.5\end{array}$ & $\begin{array}{ll}6^{\circ} 29^{\prime} \\
6^{\circ}\end{array}$ & 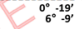 & $0^{\circ} 19^{\prime}$ & 1013.1 & 521.9 \\
\hline standard $A$ & $\begin{array}{l}\text { ant } \\
\text { pos } \\
\text { pos }\end{array}$ & $\begin{array}{l}-29.2 \\
-34.8\end{array}$ & 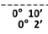 & $\begin{array}{c}0^{0}-20^{\prime} \\
0^{\circ}-29^{\prime}\end{array}$ & $\begin{array}{l}11445.2 .2 \\
1450.5\end{array}$ & $5^{0^{\circ}} 37^{\prime}$ & $\begin{array}{cc}0^{\circ}-13^{\circ} \\
5^{\circ}\end{array}$ & $0^{\circ} 13^{\prime}$ & 1032 & 523 \\
\hline Assetto di oisegro & $\begin{array}{c}\text { ant } \\
\text { pos }\end{array}$ & : & 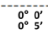 & 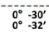 & 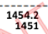 & $\begin{array}{lll}0 & 0 \\
0 & 0 \\
0\end{array}$ & 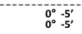 & $0^{0} 5^{\prime}$ & 1102.6 & N.C. \\
\hline Teorico di progetto & $\begin{array}{l}\text { ant } \\
\text { pos }\end{array}$ & $\begin{array}{r}-13.3 \\
-13.0\end{array}$ & 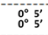 & 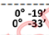 & $\begin{array}{l}14511 \\
1451 \\
1451\end{array}$ & $0^{0} \cdot 23^{\circ}$ & 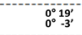 & $0^{-1} \cdot 19^{\circ}$ & 1172.9 & 535.8 \\
\hline 1 persone + okg & $\begin{array}{c}\text { ant } \\
\text { pos }\end{array}$ & $\begin{array}{ll}-22,1.1 \\
-27.8\end{array}$ & 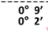 & $0^{0}-3^{\circ}$ & $\begin{array}{l}1447,3 \\
1450.6\end{array}$ & $\begin{array}{l}0^{\circ} \cdot 0^{\prime} \\
4^{\circ} 30^{\prime}\end{array}$ & $\begin{array}{l}0^{0}-12^{\prime} \\
4^{\circ}-18^{\prime}\end{array}$ & $0^{0} 12^{\prime}$ & 1000 & 528.9 \\
\hline 1 Persone + $430 \mathrm{~kg}$ & $\begin{array}{l}\text { ant } \\
\text { pos }\end{array}$ & $\begin{array}{l}-18.7 \\
20.5\end{array}$ & $\begin{array}{ll}08 \\
0.58\end{array}$ & ${ }^{0}-14^{\circ}$ & $\begin{array}{l}1449.3 \\
1451.5\end{array}$ & $.3^{0^{\circ}-19^{\prime}}$ & 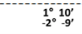 & $-1^{\circ}-10^{\prime}$ & 1362.8 & 632.1 \\
\hline 2 Persone $+20 \mathrm{~kg}$ & $\begin{array}{l}\text { ant } \\
\text { pos }\end{array}$ & $\begin{array}{l}-117.4 \\
-16.6\end{array}$ & $\begin{array}{ll}0 \\
0 \\
0\end{array}$ & $\begin{array}{c}0^{\circ}-16^{\prime} \\
0^{\circ}-30^{\prime}\end{array}$ & 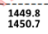 & $2^{0^{\circ}} 36^{\prime}$ & $\begin{array}{ll}0 \\
2^{\circ} 31^{\prime}\end{array}$ & $0^{-6} 4^{\prime}$ & 1065.1 & 537.6 \\
\hline 2 persone + $360 \mathrm{~kg}$ & $\begin{array}{l}\text { ant } \\
\text { pos }\end{array}$ & $\begin{array}{l}-13.5 \\
18.2\end{array}$ & 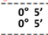 & 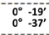 & $\begin{array}{l}14551.13 \\
1451.4\end{array}$ & 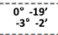 & 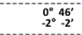 & $0^{0}-46^{\circ}$ & 1326.2 & 613.3 \\
\hline 4 persone + $205 \mathrm{~kg}$ & $\begin{array}{l}\text { ant } \\
\text { pos }\end{array}$ & $\begin{array}{l}-15.3 \\
17.9 \\
17.9\end{array}$ & $\begin{array}{ll}0^{\circ} \cdot 6 \\
0^{\circ} 5^{\prime}\end{array}$ & $\begin{array}{c}0^{\circ}-17 \gamma^{\circ} \\
0^{-}-37^{\prime}\end{array}$ & $\begin{array}{l}1450.7 \\
1451.4\end{array}$ & $\begin{array}{ll}-2^{0}-46^{\circ} \\
0^{\circ}\end{array}$ & $\begin{array}{l}-11^{6} \\
-1^{\circ}-45^{\prime}\end{array}$ & $-1^{0}-1^{\prime}$ & 1330.8 & 579.5 \\
\hline 3 Persone + $30 \mathrm{~kg}$ & $\begin{array}{l}\text { ant } \\
\text { pos }\end{array}$ & $\begin{array}{l}-1.3 .3 \\
-3.7\end{array}$ & $\begin{array}{ll}0 \% \\
0.6\end{array}$ & $\begin{array}{c}0_{0}^{0}-17^{\prime} \\
0^{0}-32^{\prime 2}\end{array}$ & $\begin{array}{l}1450.7 \\
1450.9\end{array}$ & $0^{\circ} 29^{\circ}$ & $\begin{array}{ll}0 \% \\
0^{\circ}+110^{\circ}\end{array}$ & $0^{0}-11^{\prime}$ & 1132.5 & 537.7 \\
\hline
\end{tabular}

Figure 9 - Report table

Beginning of the study, whole vehicle structure has modelled and meshed via simulation software. Concerning the subcomponents and suspension system of the vehicle, required parameters such as weight, material, gravity center, load-deflection characteristics etc. have been provided to the simulation software. After all static conditions have been simulated mathematically, virtual model has exposed to defined loads and vehicle body inclination values under defined loading conditions have been calculated by the software. All the results have reported by the simulation software as shown in Figure 9.

\subsection{Evaluation of Analysis Report and Required Values Definition}

Analysis report contains many other information. For example; effects of different loading conditions regarding to production steps, loading impacts on critical components, other distance and angle values belongs to specific parts etc. In order to calculate the cut-off line position changes or to perform required controls, correct values belong to correct loading conditions need to be found out from the report.

In this present study, M1 category passenger car has been examined and related loading conditions shown in Figure 10 have been considered accordingly.

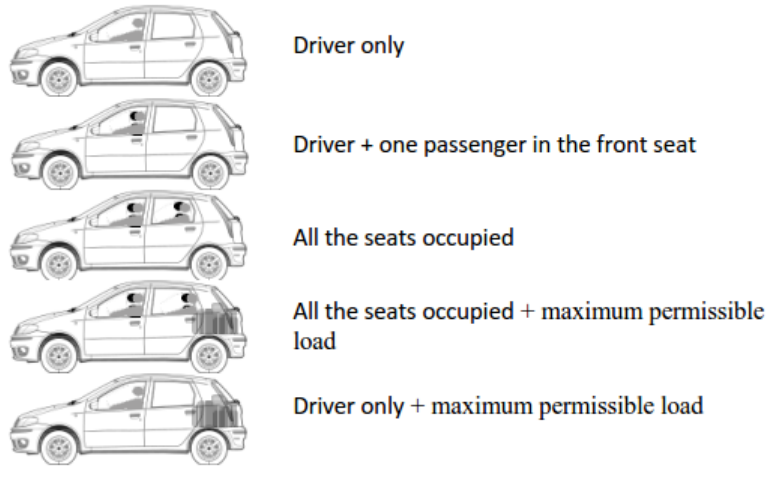

Figure 10 - ECE R48, Defined loading conditions for M1 category vehicles (4)

Five different loading conditions are descripted in related regulation (4). First and second conditions have been combined by considering the worst case. Thus, five loading conditions have been simplified into four levels (joining the $1^{\text {st }}$ to $2^{\text {nd }}$ in one only) in order to make leveling control as much as simple for the driver. After simulation with defined conditions, analysis report has been checked and related conditions have been found. Required inclination values of related loading conditions have been identified as shown in Figure 11.

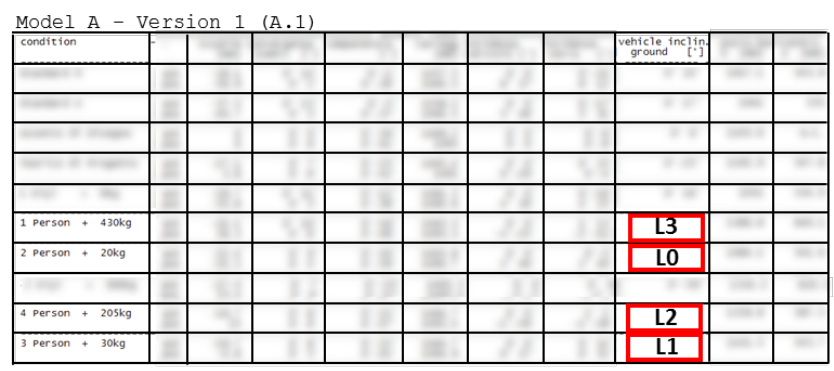

Figure 11 - Required inclination values of related loading conditions in the analysis report

\subsection{Definition of Common Angular Values for Each Controller Level}

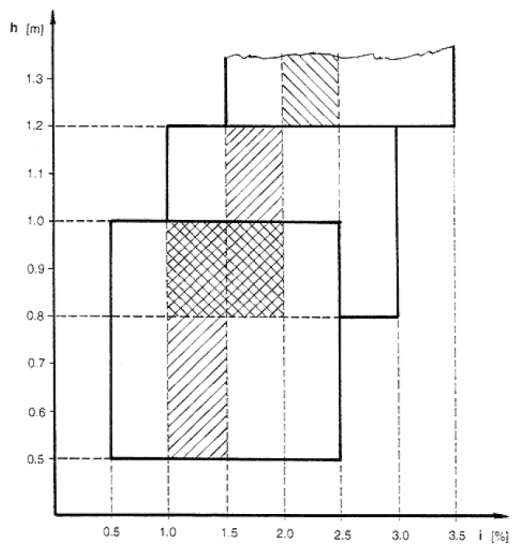

Dark area: Limits for initial downward inclination to declare

Light area: Limits for deviations.

h: Height of the vehicle

\%: Inclination value as percentage

Figure 12 - Regulative limits for Cut-Off line position (4) Allowed inclination values of the cut-off line is defined in regulations (4) as shown in Figure 12. In this graph, allowed 
range of initial downward inclination to be declared by manufacturer and allowed range of deviated inclination are figured clearly based on dipped beam height.

In this present study, examined vehicle has rear luggage boot and declared initial downward inclination was $1.0 \%$. Declared initial downward inclination is very close to upper limit (0.5\%). Therefore, maximum inclination values of each loading condition have been assigned to related controller level. In this way, all deviations which come from different versions/accessories move the cut-off position downward, thereby wider tolerance range has been provided for displacement of cut-off line position. In accordance with mentioned purpose, each inclination values belong to every different configured (different version) vehicles have been calculated under effect of defined loading conditions and tabulated as Table 3 by getting correct values from analysis report.

Table 3 - Calculated inclination values table for every version

\begin{tabular}{|c|c|c|c|c|}
\hline & \multicolumn{4}{|c|}{ Controller Level Positions } \\
\cline { 2 - 5 } & 0 & 1 & 2 & 3 \\
\hline $\begin{array}{c}\text { Model A } \\
\text { Version 1 }\end{array}$ & $L 0_{A 1}$ & $L 1_{A 1}$ & $L 2_{A 1}$ & $L 3_{A 1}$ \\
\hline $\begin{array}{c}\text { Model A } \\
\text { Version 2 }\end{array}$ & $L 0_{A 2}$ & $L 1_{A 2}$ & $L 2_{A 2}$ & $L 3_{A 2}$ \\
\hline $\begin{array}{c}\text { Model A } \\
\text { Version 3 }\end{array}$ & $L 0_{A 3}$ & $L 1_{A 3}$ & $L 2_{A 3}$ & $L 3_{A 3}$ \\
\hline $\begin{array}{c}\text { Model A } \\
\text { Version 4 }\end{array}$ & $L 0_{A 4}$ & $L 1_{A 4}$ & $L 2_{A 4}$ & $L 3_{A 4}$ \\
\hline
\end{tabular}

In Table 3 every L0 value has been considered as starting point of leveling system belongs to related vehicle. At the end of production line, cut-off line position of every vehicle has been positioned by using manual leveling mechanism of headlamp (explained in 1.4.1) according to declared initial downward value under their own L0 conditions. For the rest of defined loading conditions (L1, L2, L3), cut-off line position will be adjusted by electrical leveling system of headlamp as explained in 1.4.2.

For example: In production line, the body of Vehicle ${ }_{\mathrm{A} 1}$ (Configured vehicle according to Version 1 of Model A) has been made inclined with a controllable bench up to calculated value in order to simulate L0 loading conditions described in Table 2. In this inclined condition of Vehicle ${ }_{\mathrm{A} 1}$, cut-off line position has been positioned to $1.0 \%$ downward as declared.
The stroke value of headlamp leveler motor pivot has been kept as maximum.

In order to define common angular values for each level of controller, difference values between L0 and the rest of loading conditions have been calculated singly for each version (see Formula 1). The values found with this calculation show deviations of cut-off line position under defined loading conditions for each version of the model (see Table $4^{1}$ ).

$$
P X_{[\text {Model,Version }]}^{1}=L X_{[\text {Model,Version }]}^{1}-L 0_{[\text {Model,Version }]} \text { Formula } 1
$$

After these calculations, maximum deviation values have been determined for each controller position. (see Table 5) These determined values have been defined as common inclination values to be compensated by the electrical leveling system of headlamp in running of concerning controller position. Smaller deviation values would position the cut-off line downward which wider tolerance range permitted.

$$
\begin{aligned}
& P X_{\text {max }}^{1}=\max \left(P X_{[\forall \text { model }, \forall \text { version }]}^{1}\right) \\
& P X_{\min }^{1}=\min \left(P X_{[\forall \text { model }, \forall \text { version }]}^{1}\right)
\end{aligned}
$$

Formula 2

Formula 3

Table 5 - Maximum and minimum values

\begin{tabular}{|c|c|c|}
\hline Position & $\min ^{1}$ & $\max ^{1}$ \\
\hline 0 & - & - \\
\hline 1 & $P 1_{\min }=\min \left(P 1_{A 1}, P 1_{A 2}, P 1_{A 3}, P 1_{A 4}\right)$ & $P 1_{\max }=\max \left(P 1_{A 1}, P 1_{A 2}, P 1_{A 3}, P 1_{A 4}\right)$ \\
\hline 2 & $P 2_{\min }=\min \left(P 2_{A 1}, P 2_{A 2}, P 2_{A 3}, P 1_{A 4}\right)$ & $P 2_{\max }=\max \left(P 2_{A 1}, P 2_{A 2}, P 2_{A 3}, P 2_{A 4}\right)$ \\
\hline 3 & $P 3_{\min }=\min \left(P 3_{A 1}, P 3_{A 2}, P 3_{A 3}, P 3_{A 4}\right)$ & $P 3_{\max }=\max \left(P 3_{A 1}, P 3_{A 2}, P 3_{A 3}, P 3_{A 4}\right)$ \\
\hline
\end{tabular}

In this present study, class M1 vehicle with rear luggage boot has been examined. Therefore, maximum ${ }^{1}$ deviation values have been taken into calculations.

\subsection{Software Update Necessity Check for Main Controller Unit Based On Versions}

Every difference value between maximum and minimum values shows maximum deviation of vehicle body inclinations based on versions which mean different configuration or major modification for each controller leveling position (). This deviation values mean also the maximum deviation of the cut-off line position for each loading condition level of the controller. Possible maximum deviation of the cut-off line position for each controller level need to be less than allowed regulative tolerance range shown in Figure 13 as . Otherwise, defined common controller level is not able to fulfill cut-off position requirements for all versions of the

${ }^{1} X=1,2,3$ (Manufacturer defined cut-off line position controller levels (except 0)

Table 4 - LX - L0 table for every version

\begin{tabular}{|r|c|c|c|c|c|c|c|}
\hline & \multicolumn{3}{|c|}{$\begin{array}{c}\text { Loading conditions } \\
\text { based Inclination } \\
\text { Values }\end{array}$} & Position 1 & Position 2 & Position 3 \\
\cline { 2 - 8 } & $\mathrm{L} 0$ & $\mathrm{~L} 1$ & $\mathrm{~L} 2$ & $\mathrm{~L} 3$ & $\mathrm{~L} 1-\mathrm{L} 0$ & $\mathrm{~L} 2-\mathrm{L} 0$ & $\mathrm{~L} 3-\mathrm{L} 0$ \\
\hline $\begin{array}{r}\text { Model A } \\
\text { Version 1 }\end{array}$ & $L 0_{A 1}$ & $L 1_{A 1}$ & $L 2_{A 1}$ & $L 3_{A 1}$ & $P 1_{A 1}=L 1_{A 1}-L 0_{A 1}$ & $P 2_{A 1}=L 2_{A 1}-L 0_{A 1}$ & $P 3_{A 1}=L 3_{A 1}-L 0_{A 1}$ \\
\hline $\begin{array}{r}\text { Model A } \\
\text { Version 2 }\end{array}$ & $L 0_{A 2}$ & $L 1_{A 2}$ & $L 2_{A 2}$ & $L 3_{A 2}$ & $P 1_{A 2}=L 1_{A 2}-L 0_{A 2}$ & $P 2_{A 2}=L 2_{A 2}-L 0_{A 2}$ & $P 3_{A 2}=L 3_{A 2}-L 0_{A 2}$ \\
\hline $\begin{array}{r}\text { Model A } \\
\text { Version 3 }\end{array}$ & $L 0_{A 3}$ & $L 1_{A 3}$ & $L 2_{A 3}$ & $L 3_{A 3}$ & $P 1_{A 3}=L 1_{A 3}-L 0_{A 3}$ & $P 2_{A 3}=L 2_{A 3}-L 0_{A 3}$ & $P 3_{A 3}=L 3_{A 3}-L 0_{A 3}$ \\
\hline $\begin{array}{r}\text { Model A } \\
\text { Version 4 }\end{array}$ & $L 0_{A 4}$ & $L 1_{A 4}$ & $L 2_{A 4}$ & $L 3_{A 4}$ & $P 1_{A 4}=L 1_{A 4}-L 0_{A 4}$ & $P 2_{A 4}=L 2_{A 4}-L 0_{A 4}$ & $P 3_{A 4}=L 3_{A 4}-L 0_{A 4}$ \\
\hline
\end{tabular}


model.

Table 6 Maximum deviations between versions

\begin{tabular}{|c|c|}
\hline Position & $\Delta P$ \\
\hline 0 & - \\
\hline 1 & $\Delta P 1=P 1_{\max }-P 1_{\text {min }}$ \\
\hline 2 & $\Delta P 2=P 2_{\max }-P 2_{\text {min }}$ \\
\hline 3 & $\Delta P 3=P 3_{\max }-P 3_{\text {min }}$ \\
\hline
\end{tabular}

In this present study, difference values between maximum and minimum values have been formulated as Table 6 for examined versions of the model. Each value has been checked that if it was less than 1,5\% because of $1.0 \%$ declared initial downward inclination value as per ECE Reg 48. (4)

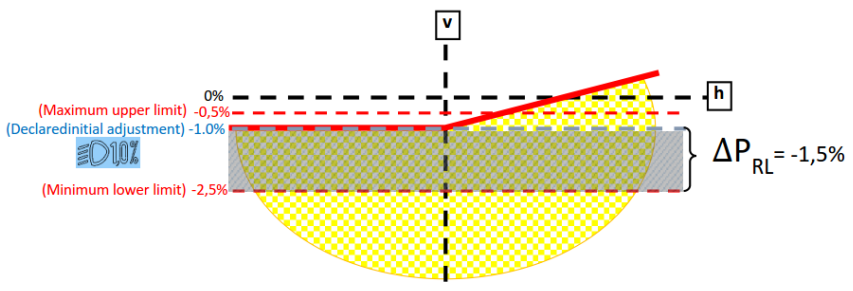

Figure 13 - Nominal cut-off position belongs to M1 category vehicle with $1.0 \%$ initial downward inclination

If then common controller output value can be used for Level $\mathrm{X}^{1}$.

If any was greater than $1,5 \%$, that means common controller output value cannot be enough to keep all versions' cut-off line positions in allowed regulative range. In this case, versions need to be divided into two or more groups and specific output values need to be assigned for each defined group.

After determination of each value and evaluation of each value, in case of any change on due to new configuration or modification, defined common output values need to be changed and main controller software needs to be updated accordingly. If any over ranged and regrouping necessity occur as mentioned above, main controller software needs to be updated again.

\subsection{Stroke Value Calculation of Headlamp Leveling Motor}

All angular deviations come from vehicle body inclination changes under loading condition impacts need to be corrected by tilting dipped beam function in reverse direction to keep the cut-off line position in allowed range. Tilting of dipped beam is mainly realized by electrical leveler motor. The shaft of the motor pushes dipped beam light source with linear movement from vertical adjustment point and causes to rotate it around fix point (horizontal axle in 3D) slightly. This slight rotation of dipped beam moves the cutoff line vertically.

Angular deviations to be corrected by leveling motor have been defined in Table 5. Linear stroke values have been formulated by considering geometrical relations as shown Figure 14.

Formulation of required stroke values for each controller level:

$$
\begin{aligned}
& \theta_{X^{1}}=P_{X_{\max }^{1}} \\
& \rightarrow \tan \left(P_{X^{1}}\right)=\frac{S_{X^{1}}}{D} \\
& \rightarrow S_{X^{1}}=D \times \tan \left(P_{X_{\text {max }}^{1}}\right)
\end{aligned}
$$

Formula 4

Table 7 - Required stroke values of leveler motor based on controller positions

\begin{tabular}{|c|c|}
\hline Position & $\boldsymbol{S}$ \\
\hline 0 & - \\
\hline 1 & $S 1=D \times \tan \left(P 1_{\max }\right)$ \\
\hline 2 & $S 2=D \times \tan \left(P 2_{\max }\right)$ \\
\hline 3 & $S 3=D \times \tan \left(P 3_{\max }\right)$ \\
\hline
\end{tabular}

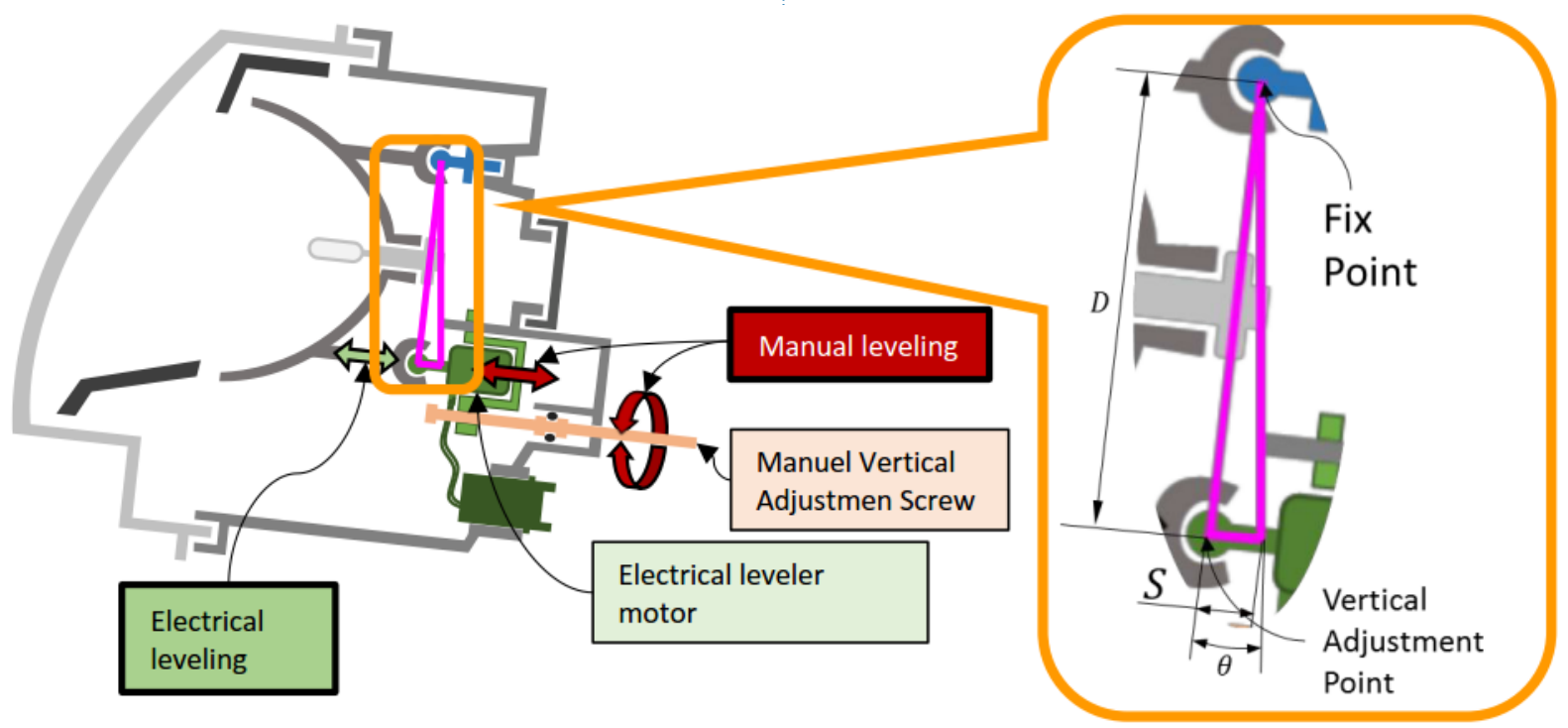

$D$ : Distance between fix point and vertical adjustment point.

$\theta$ : Angular deviation comes from loading $\theta_{X^{1}}=P_{X_{\max }^{1}}$

$S$ : Required motor stroke in order to compensate occurred angular deviation

Figure 14 - Loading conditions' influence over dipped beam 


\subsection{Tension Value Calculation of Headlamp Leveling Motor}

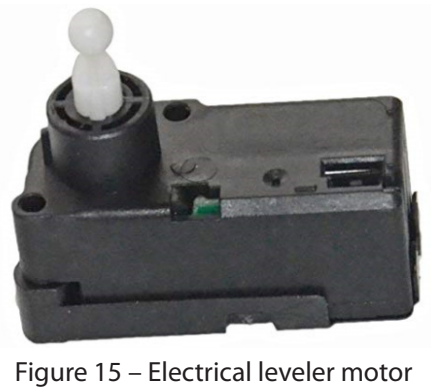

Electrical leveling motors are kind of compact products which are composed of mechanical system and electronical unit. Mechanical system converts radial movement into linear movement for the shaft and electronical unit controls the stroke of the shaft precisely (see Figure 15).

Linear stroke value of the shaft can be calculated with the stroke-tension diagram which defined by the motor manufacturer. (see Figure 16 for example)

In this study, stroke-tension diagram as in Figure 16 has been examined due to commonly usage.
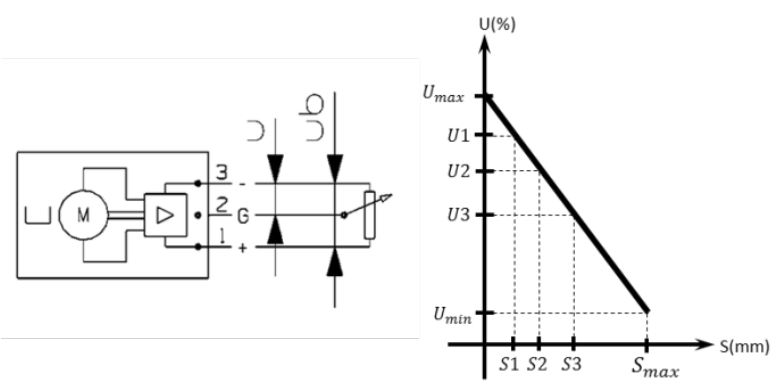

Figure 16 - Example Stroke-Tension diagram

In this issued diagram, required approximate tension values for defined stroke values in Table 7 can be determined graphically. For more accurate tension values, the diagram needs to be formulated mathematically.

Stroke-Tension diagram in Figure 16 has been formulated by referring to linear equation.

Equation of a line given two points:

$$
\frac{y_{2}-y_{1}}{x_{2}-x_{1}}=\frac{y-y_{2}}{x-x_{2}}
$$

Rearranged formulation according to stroke-tension diagram of the leveler motor:

If ; then;

$$
\begin{aligned}
& \text { If } ; \frac{U_{\min }-U_{\max }}{S_{\max }-0}=\frac{U-U_{\min }}{S-0} \text { then; } U=S \times\left(\frac{U_{\min }-U_{\max }}{S_{\max }}\right) \\
& U_{X^{1}}=S_{X^{1}} \times\left(\frac{U_{\min }-U_{\max }}{S_{\max }}\right)
\end{aligned}
$$

Final stroke values have been defined in Table 8. Main control unit software can be updated in order to generate correct tension values for each controller level based on defined loading conditions. Cut-off line position is kept in allowed range by receiving correct tension value for each related loading condition.
Table 8 - Required tension values of leveler motor based on controller positions

\begin{tabular}{|c|c|}
\hline Position & $U$ \\
\hline 0 & $U_{\max }$ \\
\hline 1 & $U_{1}=S_{1} \times\left(\frac{U_{\min }-U_{\max }}{S_{\max }}\right)$ \\
\hline 2 & $U_{2}=S_{2} \times\left(\frac{U_{\min }-U_{\max }}{S_{\max }}\right)$ \\
\hline 3 & $U_{3}=S_{3} \times\left(\frac{U_{\min }-U_{\max }}{S_{\max }}\right)$ \\
\hline
\end{tabular}

\section{RESULTS}

This present study is concluded that configuration changes, major modifications, or new version of model applications on the vehicle make necessary to be checked availability of actual cut-off vertical positions and output values of the headlamp aiming software.

Control method of actual cut-off vertical positions availability and calculations of new required tension values have been formulated. These formulas are also useful for coding and programming in order to automate controlling.

Following parameters and information have to be clarified in order to perform required controls:

- Valid regulative restrictions such as loading conditions, allowed tolerance ranges for related markets.

- Declared initial downward inclination value of the subjected model.

- All inclination values for each different configured or modified vehicles based on defined loading conditions.

- Type, structure and category information of the subjected model.

- Structure, technology, dipped beam referencing system of the subjected headlamp.

- Stroke-Tension diagram of subjected electrical leveler motor.

With this method, possible major issues and modifications during homologation phase have been eliminated and time losses have been minimized.

\section{REFERENCES}

[1] Design Of An Automotive Headlamp Considering Style And Perfomance. Tom K. Philip, M. Sivapragasam, Vignesh Ravichandran. 2, Bangalore : Department of Automotive and Aeronautical Engineering, 2013, SASTECH Journal, Vol. 12.

[2] Glare From Following Vehicles. L., Paul. 237-242, OLSON : SAE Transactions, 1990, Vol. vol. 99.

[3] IMPORTANCE OF CUT-OFF LINE. Targosinski, Tomasz. 3, 2012, Journal of KONES Powertrain and Transport, Vol. 19.

[4] United Nations Economic Commission for Europe Vehicle Regulations, Reg. 48 - Rev.7. Reg.48 Rev.7.

[5] United Nations Economic Commission for Europe Vehicle Regula- 
tions, Reg. 112 - Rev.2.

[6] HOT ROD Hotline. [Online] https://www.hotrodhotline.com/headlights-part-2-lowhigh-beams.

[7] Automobiles, Fiat Chrysler. EGEA User Manual. 2016.

[8] Design offree-formreflectorforvehicleLEDlow-beamheadlamp. Chung-YuTsai. 2016, Optics Communications.

[9] Official Journal of the European Union - Directive 2007/46/EC. 